\title{
Denem \\ COVID-19 Risk Perception and Confidence among Clinical Dental Students: Impact on Patient Management ${ }^{\dagger}$
}

\author{
Mariana Morgado ${ }^{1}\left(\mathbb{D}\right.$, José João Mendes ${ }^{1,2}$ (D) and Luís Proença ${ }^{2,3, *(\mathbb{D})}$ \\ 1 Clinical Research Unit (CRU), Centro de Investigação Interdisciplinar Egas Moniz (CiiEM), \\ Egas Moniz-Cooperativa de Ensino Superior CRL, 2829-511 Almada, Portugal; \\ mmorgado@egasmoniz.edu.pt (M.M.); jmendes@egasmoniz.edu.pt (J.J.M.) \\ 2 Evidence-Based Hub, CiiEM, Egas Moniz-Cooperativa de Ensino Superior CRL, 2829-511 Almada, Portugal \\ 3 Quantitative Methods for Health Research (MQIS), CiiEM, Egas Moniz-Cooperativa de Ensino Superior, \\ CRL, 2829-511 Almada, Portugal \\ * Correspondence: lproenca@egasmoniz.edu.pt \\ + Presented at the 5th International Congress of CiiEM-Reducing inequalities in Health and Society, Online, \\ 16-18 June 2021.
}

check for

updates

Citation: Morgado, M.; Mendes, J.J.; Proença, L. COVID-19 Risk

Perception and Confidence among Clinical Dental Students: Impact on Patient Management. Med. Sci. Forum 2021, 5, 26. https://doi.org/10.3390/ msf2021005026

Academic Editors: Helena Barroso and Cidália Castro

Published: 21 July 2021

Publisher's Note: MDPI stays neutral with regard to jurisdictional claims in published maps and institutional affiliations.

Copyright: (c) 2021 by the authors. Licensee MDPI, Basel, Switzerland. This article is an open access article distributed under the terms and conditions of the Creative Commons Attribution (CC BY) license (https:// creativecommons.org/licenses/by/ $4.0 /)$.

\begin{abstract}
This study aimed to assess COVID-19 perceived risk, confidence and its impact on potentially infected patients' management practices, in a clinical dental education setting. The survey was conducted by application of a self-administered questionnaire amid the COVID-19 pandemic. Results indicate high COVID-19 perceived risk and confidence levels ( $86.7 \%$ and $72.8 \%$, respectively). A significantly lower risk perception was identified for individuals classifying COVID-19 as a moderately dangerous disease and confidence was significantly lower for women and for individuals not previously exposed to confirmed or suspected cases of COVID-19. No factor-related significant differences were found on potentially infected patients' management practices.
\end{abstract}

Keywords: dental education; clinical education; patient management; COVID-19 risk perception

\section{Introduction}

COVID-19, caused by the coronavirus SARS-CoV-2, was identified as one of the most impacting infectious diseases of modern times [1]. During the ongoing pandemic period, besides causing a serious threat to human health, COVID-19 had an enormous impact on the education processes, particularly in the clinical context [2]. Due to the inherent characteristics of the clinical dental environment, students face additional challenges, since they have to deal with an emerging infectious disease in the community while conducting their practical learning [3].

A misplaced COVID-19 perceived risk and related confidence can have direct consequences on clinical attitudes and patient management [4].

Thus, it is imperative to study the COVID-19 perceived risk and confidence of dental students, in a clinical context, in order to identify weaknesses in the related health education processes and to find pathways to develop and implement new educational models to use under these circumstances.

\section{Materials and Methods}

The study included 244 participants, 177 senior under-graduate students and 67 recent graduates from the Integrated Master's Degree in Dentistry conducting their practical learning at Egas Moniz Dental Clinic, a university dental clinic located in the southern Lisbon area (Almada, Portugal). The survey, conducted through the application of an anonymous self-administered questionnaire (SAQ), preceded by informed consent, took place from November 2020 to March 2021, during the most impacting phase of the COVID19 pandemic in Portugal. COVID-19 self-perceived risk and confidence levels were assessed 
through numerical scores obtained from the individual answers, expressed in a 5-point Likert scale, to representative questions of each domain. The SAQ was adapted from [1], and its reliability, evaluated using the Cronbach alpha, was 0.64 . For ease of data handling and interpretation, the score was converted to a percentage scale. Data were analyzed using descriptive and inferential statistical methodologies. The present work is part of an ongoing research project (Healthcare Education and Pedagogical Innovation) approved by the Egas Moniz Ethics Committee.

\section{Results and Discussion}

Results indicate an overall high COVID-19 perceived risk and confidence (mean values $86.7 \%$ and $72.8 \%$, respectively). No significant differences were found in risk perception when considering a previous infection $(p=0.499)$ or a possible exposition to confirmed or suspected cases $(p=0.727)$. However, a significantly lower risk perception $(p=0.014)$ was identified for individuals classifying COVID-19 as a moderately dangerous disease when comparing with the ones that classify it as very dangerous (mean values 84.4 vs. $87.9 \%$ ). Confidence was found to be significantly lower for women $(p=0.001)$ and for individuals not previously exposed to confirmed or suspected cases of COVID-19 $(p=0.027)$. No relevant correlation was found between COVID-19 risk perception and confidence levels (rho $=0.07, p=0.296$ ).

When considering the attitudes towards the management of a patient exhibiting SARSCoV-2 infection-like symptoms, $65.6 \%$ reported proceeding with the treatment and asking the patient to go to the hospital afterwards, $26.6 \%$ referencing the patient to the hospital without providing treatment and $7.8 \%$ refusing to provide dental treatment. Even so, no significant differences were found when accounting for the attitudes and practices in the management of patients exhibiting SARS-CoV-2 infection-like symptoms, as a function of the disease perceived risk $(p=0.064)$ and reported confidence $(p=0.713)$ levels.

In light of these results, it is recommended to improve COVID-19 risk perception and confidence levels by using dedicated measures in the clinical dental education context. This could be achieved by developing more resilient and dedicated clinical educational models, applicable in the context of a global public health emergency, optimizing the public health education of future professionals.

Institutional Review Board Statement: The study was conducted according to the guidelines of the Declaration of Helsinki, and approved by the Ethics Committee of Instituto Universitário Egas Moniz (no. 906 of 26 November 2020).

Informed Consent Statement: Informed consent was obtained from all subjects involved in the study.

Data Availability Statement: The data used to support the findings of this study are available from the corresponding author (L.P.) upon request.

Conflicts of Interest: The authors declare no conflict of interest.

\section{References}

1. Ding, Y.; Du, X.; Li, Q.; Zhang, M.; Zhang, Q.; Tan, X.; Liu, Q. Risk perception of coronavirus disease 2019 (COVID-19) and its related factors among college students in China during quarantine. PLoS ONE 2020, 15, e0237626. [CrossRef] [PubMed]

2. Taghrir, M.H.; Borazjani, R.; Shiraly, R. COVID-19 and Iranian Medical Students; A Survey on Their Related-Knowledge, Preventive Behaviors and Risk Perception. Arch. Iran Med. 2020, 23, 249-254. [CrossRef] [PubMed]

3. Meng, L.; Hua, F.; Bian, Z. Coronavirus Disease 2019 (COVID-19): Emerging and Future Challenges for Dental and Oral Medicine. J. Dent. Res. 2020, 99, 481-487. [CrossRef] [PubMed]

4. Almulhim, B.; Alassaf, A.; Alghamdi, S.; Alroomy, R.; Aldhuwayhi, S.; Aljabr, A.; Mallineni, S.K. Dentistry Amidst the COVID-19 Pandemic: Knowledge, Attitude, and Practices Among the Saudi Arabian Dental Students. Front. Med. 2021, 8, 400. [CrossRef] [PubMed] 